\title{
Graciela Calderón Díaz Barriga (1931-2022)
}

Acta Botanica

Mexicana

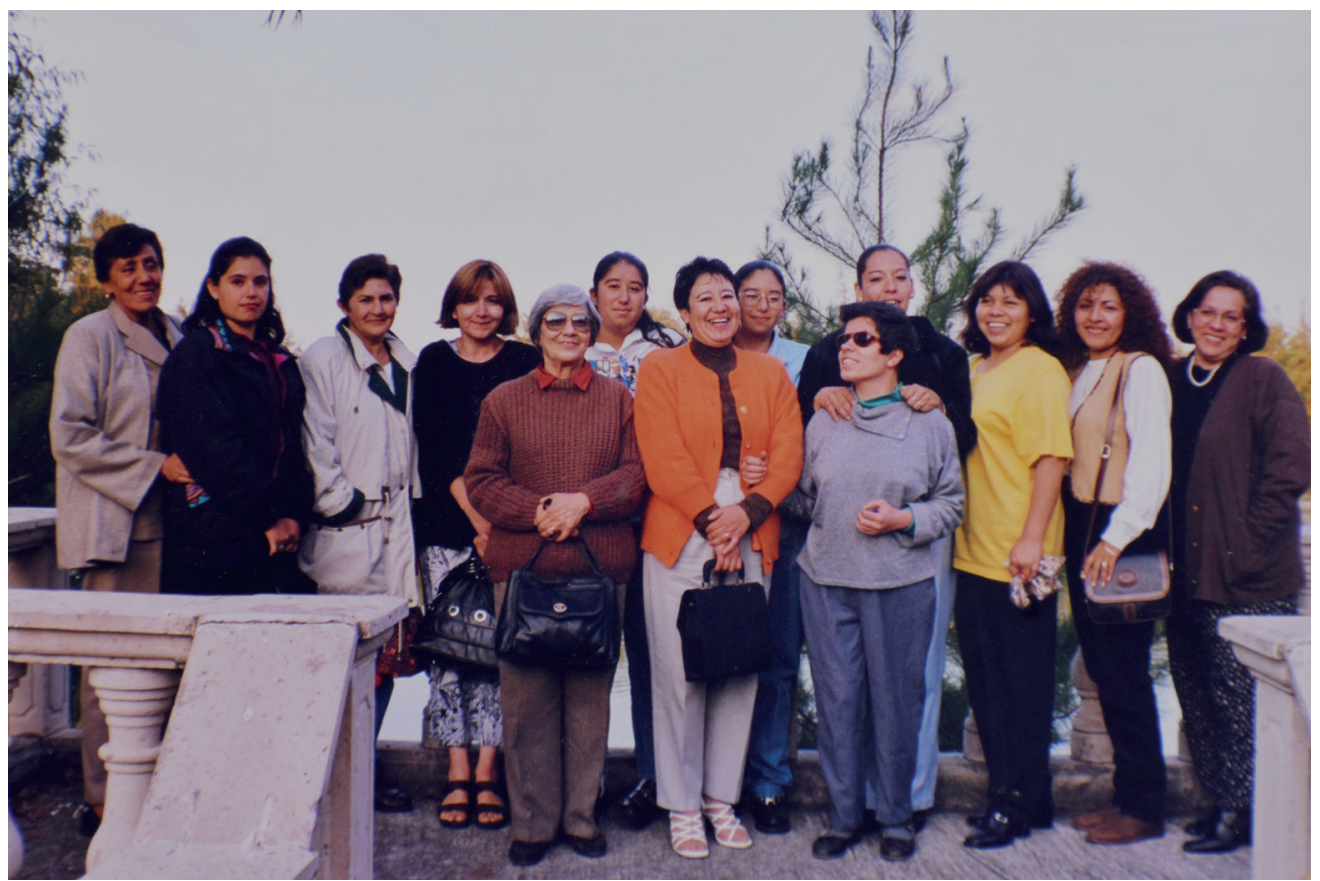

La "familia" siempre creciente de la maestra Graciela Calderón, en el año 1998, después de una comida en el restaurante Campestre Alemán, Arocutín, Michoacán. Primera fila, de izquierda a derecha: Maestra Graciela Calderón Díaz Barriga, Rosa Elena Murillo Guizar, Anita Rzedowski Calderón; segunda fila, de izquierda a derecha: Catalina Acosta, Ana Lilia Medellín, Lourdes de Patiño, Dra. Socorro GonzálezElizondo, Irene Anai Aguilar Murillo, Rosa Elena Aguilar Murillo, Rosa María Molina González, Minerva Martínez Calderón, Adriana Ivonne Silva Vargas y Biól. Rosa María Murillo Martínez (Crédito: Sergio Zamudio Ruiz).

Rosa Elena Murillo Guizar,2,2

\section{A mi querida maestra Chela, como cariñosamente todos solíamos llamarla}

No hablaré de la destacada investigadora, botánica de muy alto nivel, reconocida nacional e internacionalmente, académica productiva de gran talla y formadora de infinidad de destacados botánicos, así como pilar fundamental en la creación del Centro Regional del Bajío, junto con su querido esposo Jerzy Rzedowski Rotter. Hablaré de la maravillosa
${ }^{1} J u b i l a d a$ del Instituto de Ecología, A.C., Centro Regional del Bajío, Red de Diversidad Biológica del Occidente Mexicano, Avenida Lázaro Cárdenas 253, 61600 Pátzcuaro, Michoacán, México.

${ }^{2}$ Autor para la correspondencia: murilloguizar@hotmail. com
Recibido: 8 de febrero de 2022

Revisado: 8 de febrero de 2022

Aceptado por Marie-Stéphanie Samain: 11 de febrero de 2022.

Publicado Primero en línea: 18 de febrero de 2022 Publicado: Acta Botanica Mexicana 129 (2022).
Citar como: Murillo Guizar, R. E. 2022. Obituario Graciela Calderón Díaz Barriga. Acta Botanica Mexicana 129: e2022. DOI: https://doi.org/10.21829/ abm129.2022.2022

e-ISSN: 2448-7589 
mujer con gran calidad humana, sencilla de gran corazón, con la que tuve la suerte y dicha de trabajar casi 30 años.

Conocí al matrimonio Rzedowski en 1985 por recomendación de la trabajadora social del plantel Conalep en Pátzcuaro en aquel entonces, pues yo había terminado de cubrir una incapacidad por gravidez y sabían del trabajo que había desarrollado. Acudí a la cita para la entrevista realizada por los Rzedowski, desconociendo el tipo de trabajo que realizaría; el examen consistió solamente en pasar un escrito a máquina. Transcurridos unos días me llamaron para avisarme que había sido seleccionada entre otras candidatas.

En 1986 se vieron en la necesidad de rentar un inmueble para instalar las oficinas del Centro, ya que inicialmente desarrollaron su trabajo ocupando el espacio de la sala de su propia casa. En esa sala me enseñaron a montar y etiquetar ejemplares de herbario y a rotular carpetas para el intercalado de los mismos; pronto me darían más trabajo, el cual consistía en mecanografiar los manuscritos del tercer volumen de la Flora Fanerogámica del Valle de México. La maestra Chela, una persona tan inteligente, ordenada y meticulosa, tuvo a bien elaborar para mí una lista con las indicaciones, así como hojas con las medidas de los márgenes y espacios para las claves. En ese tiempo se utilizaba la máquina de escribir mecánica y había que transcribir un original y cuatro copias con papel carbón. Cuando la maestra revisaba lo elaborado y decidía hacer cambios en las claves o descripciones, me decía muy curiosa "solo póngale un parchecito con los cambios". A mí no me gustaba porque no tenía buena presentación y decidía elaborar nuevamente la hoja, y entonces ella me dijo "ya sé que se da cuenta con quién está trabajando y me da gusto". Eso me motivó, le agradezco mucho su paciencia, sus consejos y sus enseñanzas, porque me ayudaron a realizar cada vez mejor mi trabajo.

En esa época la plantilla de trabajadores era muy pequeña, ya que había solo cinco personas. Nunca hubo distinción en su trato, nos daba el mismo a todos, además era cariñosa, amable y paciente; se dirigía a nosotros siempre con una sonrisa, para ella éramos como una familia.

Era originaria de Salvatierra, Guanajuato, una ciudad que ocasionalmente visitaban y de la que a su regreso nos traía a todos dulce de ate casero, que es una delicia; decía "es para presumir las cosas ricas de mi tierra". Siempre generosa, cuando llegaba la cosecha de los chiles que tenían sembrados en su casa, los preparaba en escabeche con ayuda del Dr. Rzedowski; era un gozo saborearlos, ya que tenían un sabor único.

Alegre, animosa y siempre contenta en las reuniones que organizábamos a fin de año, nos invitaban a comer, a todo el personal acompañados por nuestra familia, al restaurante Campestre Alemán, su lugar favorito. Se sentía la unión y armonía del pequeño grupo; al término de la comida nos tomábamos la foto y decía que cada año crecía más su familia. Había otras reuniones con el personal, la más importante era cuando había que festejarla en su cumpleaños. Todos estábamos en la mejor disposición para participar, organizarnos y cooperar. Esto de alguna manera era la forma de demostrarle nuestro agradecimiento por tanto cariño y su excelente trato.

En lo personal, tengo mucho que agradecerle; siempre estaba pendiente de platicar conmigo para saber si mi familia se encontraba bien. Agradezco el apoyo invaluable que me brindó, así como sus acertados y sabios consejos. En ocasiones, cuando el Dr. Rzedowski se iba a trabajar al herbario me pasaba a su oficina y decía "venga, siéntese, vamos a platicar qué novedades ha habido". Al regresar el doctor nos encontraba platicando y ella le decía "no estamos chismeando, solo estamos poniéndonos al corriente de los acontecimientos", siempre con su buen humor.

Su sencillez y gran calidad humana se ven reflejadas en su familia, y la demostración de cariño de tanta gente que sentimos y a la que nos dolió su partida.

Hasta siempre maestra Chela, gracias por todas sus enseñanzas y cariño brindado, estará en nuestro recuerdo con esa gran sonrisa que la caracterizaba. 